This item was submitted to Loughborough's Research Repository by the author.

Items in Figshare are protected by copyright, with all rights reserved, unless otherwise indicated.

\title{
Is it pleasure or health from leisure that we benefit from most? An analysis of well-being alternatives and implications for policy
}

\section{PLEASE CITE THE PUBLISHED VERSION}

http://dx.doi.org/10.1007/s11205-015-0887-8

\section{PUBLISHER}

(c) Springer Science+Business Media

\section{VERSION}

AM (Accepted Manuscript)

\section{PUBLISHER STATEMENT}

This work is made available according to the conditions of the Creative Commons Attribution-NonCommercialNoDerivatives 4.0 International (CC BY-NC-ND 4.0) licence. Full details of this licence are available at: https://creativecommons.org/licenses/by-nc-nd/4.0/

\section{LICENCE}

CC BY-NC-ND 4.0

\section{REPOSITORY RECORD}

Downward, Paul, and Peter Dawson. 2015. "Is It Pleasure or Health from Leisure That We Benefit from Most? an Analysis of Well-being Alternatives and Implications for Policy". Loughborough University. https://hdl.handle.net/2134/17294. 
Is it pleasure or health from leisure that we benefit from most?

An analysis of well-being alternatives and implications for policy.

Paul Downward*

School of Sport Exercise and Health Sciences

Loughborough University

Ashby Road

Loughborough

UK

LE11 3TU

$+44(0) 1509226365$

p.downward@lboro.ac.uk
Peter Dawson

Department of Economics

University of East Anglia

Norwich Research Park

Norwich

UK

NR4 7JT

+44(0)1603597612

Peter.Dawson@uea.ac.uk

*Corresponding author 


\title{
Is it pleasure or health from leisure that we benefit from most? An analysis of well-being alternatives and implications for policy.
}

\begin{abstract}
International policy now constantly advocates a need for populations to engage in more physical activity to promote health and to reduce society's health care costs. Such policy has developed guidelines on recommended levels and intensity of physical activity and implicitly equates health with well-being. It is assumed that individual, and hence social, welfare will be enhanced if the activity guidelines are met. This paper challenges that claim and raises questions for public policy priorities. Using an instrumental variable analysis to value the well-being from active leisure, it is shown that the well-being experienced from active leisure that is not of a recommended intensity to generate health benefits, perhaps due to its social, recreational or fun purpose, has a higher value of well-being than active leisure that does meet the guidelines. This suggests rethinking the motivation and foundation of existing policy and perhaps a realignment of priorities towards activity that has a greater contribution to social welfare through its intrinsic fun and possibly social interaction.
\end{abstract}

\section{Key words}

Subjective Well Being; Happiness; Health; Active Leisure; Sports 


\section{Introduction}

Early policy at the beginnings of the twentieth century typically promoted sport and physical activity to improve physical fitness for the military. However, following the second world war sport became a form of social welfare policy intervention, ultimately becoming enshrined internationally in, for example, the European Sport for All Charter of 1975 and European Sports Charters of 1991 and 2001 (Houlihan, 1997; Green, 2004; Green and Houlihan, 2005, Downward et al 2009). The implication was that sport, as a form of social leisure improves well-being. Current international public policy emphasises the need for increased physical activity to improve the health of individuals, reducing their chances of disease and thereby improving their well-being (Department of Health, 2004; WHO, 2010). Consequently increasing the use of leisure time being spent in activities such as sport has been identified in the UK and internationally (GAPA/PSPAH, 2012) as a key platform for achieving physical activity guidelines and, as such, has had specific targets as a contribution towards 'Health Enhancing Physical Activity' (HEPA) (Sport England, 2013). Achievement of such targets, it is argued, will produce substantial healthcare benefits with a corresponding reduction in healthcare costs. These have been estimated to range between $£ 2$ billion (DCMS/Strategy Unit, 2002) and $£ 3$ billion in the UK.1,2

Such claims form part of a current generalised normative impetus that public resources need to be prioritised and targeted at physical activity initiatives. It is argued, for example in the UK, that policy

\footnotetext{
${ }^{1}$ http://www.sportengland.org/research/benefits-of-sport/health-benefits-of-sport/case-study-engaginginactive-people/

${ }^{2}$ In such calculations it is unclear if the costs of physical activity are accounted for. For example, though less popular in current discussion, active leisure through sport and recreational activity also has health-care costs resulting from injury (see, for example, Marshall \& Guskiewicz, 2003). There are also well-documented health concerns with competitive sport (Ljungqvist et al, 2009).
} 
“... guidelines provide recommendations on levels of physical activity which best support population level changes in health... Action and investment is urgently needed to increase population levels of physical activity in the UK in order to reap the wide reaching health, social and economic benefits."(BHF, 2013, p.2)

However, what is not at all discussed in shaping these arguments are alternative concepts of public interest and their link to competing claims with respect to resource allocation. It follows that the health-based benefits of sport are never compared to their potential social or other personal benefits. For example, from an economic theoretical perspective whilst health may be an important feature of an individual's well-being, it is not necessarily synonymous with it (Dolan et al. 2008). Ultimately well-being is connected with the overall utility that could be derived from all sorts of activities, some of which may not be necessarily healthy. The physical activity literature that drives the normative impetus noted above, in contrast, essentially treats well-being as a psychological component of health and this then gets conflated in policy with well-being generally. For example, it is argued that 'health-related quality of life specifically refers to an individual's perception of their health and wellbeing' (BHF, 2013, p.7).

This paper provides an empirical analysis to answer two related research questions that provide a challenge to this position. The first question is 'what is the value of active leisure through physical activity to individuals? The second related question is, 'is there a subsequent case to prioritise the promotion of activity of an intensity to generate health benefits versus activity that produces more general well-being benefits? Answers to these questions are provided by, for the first time in the literature, comparing the monetary estimates of the contribution of the actual minutes of sports participation, as an indication of active leisure, of various intensities, some of which have been shown to be necessary for health benefits to accrue, to an individual's subjective well-being. This is an important issue, because, 
comparing the trade-offs between the different outcomes for society from alternative courses of action has been argued to be an advantage of the approach of valuing subjective well-being (OECD, 2013).

That physical activity and sports participation, as leisure, can improve health is not in question. The physical activity and health literature is largely unanimous in concluding that there are positive impacts of physical activity generally on a wide variety of indicators of health and psychologically-defined well-being. The evidence base draws upon a variety of designs including randomised controlled trials of interventions, observational studies and large-scale analysis of correlates (Warburton, Nicol, \& Bredin, 2006). It is argued that physical activity can improve respiration and cardiovascular performance (Steyn, et al., 2005; Sofi, Capalbo, Cesari, Abbate, \& Gensini, 2008); increase muscle and bone strength, thereby reducing the incidence of fractures, particularly in the more elderly; as well as reduce the incidence of cancers (Warburton, Katzmarzyk, Rhodes, \& Shephard, 2007; Bauman, Lewicka, \& Schöppe, 2005). It is also argued that physical activity reduces the incidence of Type II diabetes (Cook, Alberts, \& Lambert, 2008; Gill \& Cooper, 2008); and, of particular importance to this paper, improve well-being by reducing depression and improving mood (Chalder et al., 2012; Krogh, Nordentoft, Sterne, \& Lawlor, 2011; Mead, Morley, Campbell, Greig, McMurdo, \& Lawlor, 2009; Camacho, Roberts, Lazarus, Kaplan, \& Cohen, 1991; Farmer et al., 1988).

A wide variety of activities can produce these benefits. In the limit physical activity is any movement in the body generated by the muscular-skeletal system and fuelled by energy expenditure (WHO, 2004). Nonetheless, it is argued that in reality this is likely to involve sport, play and game-based recreational or leisure-time physical activity, transport through walking or cycling, occupational activity, manual activity as well as household chores, which 
include housework, gardening, etc. (WHO, 2010). Naturally, therefore, research that specifically focusses on sport as physical activity reinforces the conclusions about the positive impacts of physical activity on health and well-being generally (O'Donovan et al., 2010; Haskell et al., 2007).

This evidence has been used to underpin guidelines, alluded to earlier, for recommended levels of 'Health Enhancing Physical Activity' (HEPA) (WHO, 2010). The WHO recommends as a minimum that adults aged between

"18-64 years should do at least 150 minutes of moderate-intensity aerobic physical activity throughout the week, or do at least 75 minutes of vigorous-intensity aerobic physical activity throughout the week, or an equivalent combination of moderate- and vigorous-intensity activity." (WHO 2010, p8) ${ }^{3}$

It is argued that these minimum requirements can be surpassed, with further benefits being obtained, from increasing the intensity and duration of physical activity as well as engaging in muscular strengthening. Clearly policy targets that involve enhancements in physical activity through active travel, and particularly walking and cycling, have been championed as mechanisms to promote HEPA (Pate et al., 1995; Oja et al., 1998; Cevero et al., 2003; Smith and Bird, 2004; Shephard, 2008 and Basset et al., 2008). Active leisure through sport is also recommended (Biddle et al., 2004) and, it is this view that is adopted in the UK where sport has specifically been targeted as an important contributor to HEPA (DCMS/Strategy Unit, 2002). Sports policy strategy, being delivered by Sport England, thus emphasises contributing to overall recommended physical activity guidelines through, for example, encouraging an increase in

\footnotetext{
${ }^{3}$ The minimum guidelines for children and young people aged 5-17 years are to undertake at least 60 minutes of moderate to vigorous-intensity physical activity daily. For adults aged 65 years and above minimum guidelines are for at least 150 minutes of moderate-intensity aerobic physical activity throughout the week, or do at least 75 minutes of vigorous-intensity aerobic physical activity throughout the week, or an equivalent combination of moderate- and vigorous-intensity activity (WHO 2010 p7-8).
} 
"the percentage of the adult population participating in sport, at moderate intensity, for at least 30 minutes on at least 12 days out of the last 4 weeks (equivalent to 30 minutes on 3 or more days a week" (Sport England, 2013, p1)

This 'key performance indicator' tracked by Sport England is referred to in the empirical work below as an indication of the potential to generate health from active leisure. ${ }^{4}$

Outside of the physical activity literature, economists and social scientists have begun to examine the impact of active leisure through sport and physical activity on health and wellbeing. This is as a developing strand of a well-established literature analysing the individual, social and environmental factors that are associated with well-being. Dolan et al. (2008) provide a comprehensive survey of the factors that have been investigated in the well-being literature. To illustrate its breadth, it is identified, for example, that higher income and its aspiration can increase well-being (Clarke et al., 2005; Bruni and Stanca, 2006). Personal characteristics are also analysed. These include, for example, age, in which it is identified there is a U-shaped relationship with well-being (Blanchflower and Oswald, 2008a; FerreriCarbonell and Gowdy, 2007; Cheng et al, forthcoming); gender, in which it is often found that females tend to report greater happiness (Alesina, et al., 2004; Guven et al., 2012); and ethnicity, in which it is often indicated that white ethnicity is associated with greater wellbeing (Thoits and Hewitt, 2001). However, in the latter case it can also be argued that the gap between white and other ethnicities is declining, for example in the US (Coverdill et al., 2011). Dolan et al. (2008), moreover, argue that comparisons may depend on the proportions of different ethnicities in various categorical variables in the particular analysis. The literature also argues that factors connected with social development such as higher levels of education, health and working relative to being unemployed, say, are associated with higher levels of well-being (Blanchflower and Oswald 2004; Blanchflower and Oswald 2008b; Winkelmann

\footnotetext{
${ }^{4}$ Sport as active leisure is a good vehicle for analysis in the current context as very detailed information on the intensity of its practice is possible, as detailed below in Section 3.
} 
and Winkelmann, 1998; Andersson, 2008.). Household status and social relationships have also been examined. The literature suggests that being married raises well-being compared to being divorced, separated or having suffered bereavement (Gardner and Oswald, 2006), but there are dynamic effects involved, with well-being from bereavement recovering over about an 8 year span (Lucas et al. 2003); and that divorce reduces female well-being more than males, but that remarriage can imply a recovery of levels of well-being (Clark et al. 2008). Further, Stutzer and Frey (2006) argue that there are selection effects that determine household composition. For example, marriage is more likely for happier people. Frijters et al. (2011) thus argue that household relationships have anticipation, selection and adaptation effects. Finally, papers have also examined environmental influences on well-being such as civil conflict (Welsch, 2008), German reunification (Frijters et al 2004), Russian economic transition (Frijters et al 2006) and drought (Carroll et al 2009).

A distinct emphasis of this social scientific and economic literature is that it focuses upon large-scale secondary data analysis of Official data (Dolan et al., 2008), to focus on population level implications. This is also the case, therefore, with the emergent social scientific and economic strand of this literature examining the impact of active leisure through sport and physical activity on health and well-being as compared to the physical activity and health literatures. A further distinction is that generalised, typically single-scale, measures of general health and subjective well-being are employed. Questions on the former are long-standing in national surveys. For example, they date back to 1976 in the UK with the General Household Survey, and were incorporated into subsequent surveys such as the Health Survey for England, which commenced in 1991. The reliability and the validity of the single general health scales have been shown to be strong over time, but particularly for the end-point of the scales because of their narrow range (Department of Health, 2001). 
The single summary measurement of subjective well-being is now increasingly undertaken in, and analysed from, Official surveys both in the UK and internationally and this has both allowed and been encouraged by the development of the literature noted above (See, for example, Waldron, 2010). Economic theory in particular has provided a strong rationale for quantifying subjective well-being (Powdthavee, 2010). Increased momentum for the role of well-being in public policy has taken place , therefore, based on support for an argument made, for example, by Stiglitz, Sen, \& Fitoussi (2008), that the welfare of an economy is not simply measured by Gross Domestic Product, but should reflect broader concerns with wellbeing and hence the overall quality of life This has culminated in clear UK political desire to measure well-being (Dolan et al., 2011), building upon arguments that have long been made in the UK (See, for example, Oswald, 1997). An important consequence of this development is the current review and discussion concerning the role of well-being in the evaluation of publicly funded projects in public policy generally (Dolan et al., 2011) and cost-benefit analysis in particular (See, for example, Fujiwara \& Campbell, 2011). This is not to say, that this task is unproblematic.

The complexity of measuring subjective well-being is implied in noting that surveys have measured different items including; overall life satisfaction, happiness, and the autonomy that people feel that they have over their life (i.e. Eudaimonia) (Dolan et al., 2011; OECD, 2013). Each of these, it is argued, captures theoretically distinct but related features of subjective well-being. Overall life satisfaction has been linked most closely to measuring the outcomes of conscious reflection about decisions in life, for example, connected with work or income. This has been aligned to the 'decision utility' captured in axiomatic economic theory (Kahneman, 1999; Helliwell and Barrington-Leigh, 2010). Happiness, in contrast, is seen to capture 
elements of feelings and mood and, as such, has been associated with a broader notion of 'experienced' utility connected with sentiments and relationships (Sugden, 2005; Frey, 2008). Finally, aspects of well-being captured by dimensions such as autonomy of action are more closely linked to a sense of Eudaimonia, or good psychological functioning and, are more closely linked to the psychological aspects of well-being qua health discussed in the physical activity and health literature (OECD, 2013). Overall, it is noted that there are stronger empirical relationships between the life-satisfaction and happiness measures than with measures of Eudaimonia. The current paper focusses on happiness as a broader measure of well-being to critically address the relative impact of health-related behaviours.

In the context of sport and physical activity, the emergent economic and social scientific empirical literature can be considered as comprising two strands. The first draws upon associations and does not therefore formally address causality in the relationship between sport and leisure and well-being. Becchetti et al. (2008) examine the German Socio-Economic Panel (GSOEP), using fixed-effects panel regressions, to show that life satisfaction is positively associated with the ordered frequency of attending social gatherings, attending cultural events, participation in sports, performing volunteer work and attending church or religious organizations. Based on the Taking Part Survey from the UK, Rasciute \& Downward (2010) show that binary measures of participation in sport, as well as walking and cycling activity, are jointly associated with happiness and subjectively defined general health. They find that sports participation and walking have a positive association with both the individual's health and happiness. However, whilst cycling has a positive association with health, it also appears to involve a negative association with happiness, which could be the disutility associated with traffic congestion. Downward \& Rasciute (2011) also make use of the Taking Part Survey to analyse the association between social interactions in sports participation and happiness. 
They show that the number of activities like team sports and sports undertaken with a partner such as racquet sports are associated with higher levels of happiness than those for any sport. Finally, making use of ordered regressions on Understanding Society Data, Brown, et al. (2014) identify positive associations between binary measures of moderate and mild intensity sports participation, active-creative leisure activities, as well as heritage activities, and life satisfaction. However, this was not found to be the case for sedentary activities such as reading and hobbies.

The second strand of research, in contrast, has attempted to identify causality between sport and leisure participation from the research. Lechner (2009) examines the GSOEP to identify positive impacts of a binary categorisation of sport on an objective measure of health (days unable to work) as well as two measures of subjective health (the subject's own view of their health and their satisfaction with their health), as well as ordinal indicators measuring whether the individual is worried or not about the economic situation and their general satisfaction with life. A comprehensive research design is employed in which lags are exploited to control for selection effects and confounding effects in a matching analysis. Significant effects of sport participation upon the well-being of males are identified but positive and insignificant effects for females.

Huang \& Humphreys (2010) establish a significant positive effect of a binary measure of sports participation on life satisfaction for both males and females using data from the US Behavioural Risk Factor Surveillance System. They identify causal effects through using the availability of more aggregate (county-level) counts of sports establishments as an instrumental variable. Pawlowski et al. (2011) analyse the effects of ordered measures of sports participation on happiness for a sample of European countries, making use of 
International Social Survey Data. Instrumental variables are used in the analysis including the frequency of attending a sports event, and engagement in a sports association or group Overall the results suggest that engagement in physical activity can influence happiness, but that the effects vary by age and are larger for the elderly. Becchetti et al. (2011) analyse the World Values Survey and show that the time available for collective social leisure has a positive association with life satisfaction. A recursive bivariate model is used to jointly model well-being (as an ordered variable) and the time spent in collective social leisure (as a continuous indicator), including sport. No additional identifying variables are used in the analysis but robustness checks are undertaken by using the individual's declaration of the value of time for relationships as an instrument for the time available for collective social leisure. Building upon Becchetti et al. (2008), Becchetti et al. (2012) also examines the German Socio-Economic Panel (GSOEP) to show that life satisfaction increases with an increase in the ordered frequency of engaging in leisure and social activities. The paper also makes use of the extra time available in retirement as an instrument to control for simultaneity between participation in these activities and subjective well-being. Specifically, the proportion of retirees in the population sample by age cohort for each year is used as the instrument. Humphreys et al. (2014) examine the probability of participating in physical activity or not and the subsequent probability of experiencing particular health outcomes using Canadian Community Health Survey Data. They employ a recursive bivariate probit model but directly include a variable measuring the individual's 'sense of belonging' to the community as an instrument to capture the feeling of adequacy of local amenities or a generally supportive culture towards physically activity. They find that participation in physical activity reduces the self-reported incidence of diabetes, high blood pressure, heart disease, asthma, arthritis as well as the score on a general health scale. A similar approach is used by Sarma et al. (2014) who also estimate a recursive bivariate probit model on Canadian 
Community Health Survey Data as well, but they estimate the model making use of local temperature data as an instrument, over more time periods and include workplace physical activity as a control variable. They also estimate linear instrumental variable and simple probit models to assess robustness. It is found that leisure time physical activity can reduce the probability of adverse health indicators like being overweight and obese but, unlike Humphreys et al. (2014), they do not identify a reduction in diabetes, high blood pressure and heart disease. Finally, Dolan et al. (2014) analyse Eurobarometer data in a recursive bivariate probit model of a binary measure of life satisfaction to show that, across Europe, participating in sport at least one-to-three times a month increases life satisfaction. An innovative aspect of this paper is that latent variables from a factor analysis of the perceived benefits of sports by individuals who participate in sports or not are used as instruments in the analysis. These include health, pleasure and purpose (such as to achieve objectives and to stimulate the spirit of competition). ${ }^{5}$

There are two important features of the above literature that are worth noting. The first is that active leisure, through sports, is associated with increases in both well-being and health, but, significantly that there are impacts on the former through the relational and social nature of the activity independently of an explicit focus on health (for example Becchetti et al., 2008; Becchetti et al., 2011; Downward and Rasciute, 2011 and Becchetti et al., 2012). The literature also finds that active leisure through sports can simply be 'fun' as well as healthy (Dolan et al.,

\footnotetext{
${ }^{5}$ The use of the bivariate recursive probit model discussed in this section, as opposed to, say, the bivariate probit model employed by Rasciute and Downward (2010), only corrects for endogeneity on the theoretical assumption that there is no direct feedback between the outcome (e.g. well-being) and treatment (e.g. sports participation) variables. Both models can also have the same or different sets of regressors. In this way identification of the models, that is the tractability of the model for estimation, can rely on simply having variation in the regressors (that is by 'functional form', which in this case relies on bivariate normality). There is no need for exclusion restrictions. The inclusion of the latter, that is variables in the sports participation but not well-being equation, can aid identification and improve the theoretical argument concerning causality. This is the case with the papers, and also justifies their inclusion, in the second strand of the literature.
} 
2014). The second is a methodological insight. An important feature of the second strand of research is the recognition that trying to make causal inferences about the effects of sport on health and well-being requires accounting for the simultaneity between these variables; that is that health and well-being might also influence sports participation. Failure to control for this could lead to biased estimates. With the exception of Lechner (2009) the research makes use of instrumental variable estimators.

The current paper makes use of the latter strategy in seeking to first value the impact of sports participation on well-being; and, second, to establish for the first time in the literature the relative valuations of the actual minutes of sport being undertaken of different intensities; some of which are consistent with yielding recommended health benefits. This is in order to address the question that is implicit in the first feature of the literature concerning which aspect of sports activity is valued the most. Is it health or fun and possibly social impact? The paper consequently questions the claim, popularised in policy documents drawing upon the physical activity literature, that well-being is necessarily maximised by healthy leisure. If this is not the case then this also raises questions with respect to the priorities for public policy. The paper proceeds as follows. Section 2 outlines the economic theoretical approach to valuing the contribution of sport as active leisure to subjective well-being. It also outlines the data employed in the analysis and estimation strategy. The validity of the instruments is discussed in this section. Section 3 outlines the main results of the paper. Section 4 discusses the results. Conclusions follow in section 5 . 


\section{Methods}

\subsection{Theory}

The approach to valuing subjective well-being adopted in this paper has its foundation in Clark \& Oswald (2002) and has been employed elsewhere (see for example, Blanchflower \& Oswald, 2004; Frijters et al., 2011). It maintains that well-being can be viewed as a measurement of the indirect utility of individuals; that is the inverse function that converts unobserved utility, as a function of the consumption of physical resources, into an equivalent function of the monetary values of those resources, that is, prices and incomes. Under such circumstances it is possible to postulate the following relationship as in equation 1 .

$$
W B_{i}=\beta_{1}+\beta_{2} S_{i}+\beta_{3} I_{i}+\beta_{4} Z_{i}+\varepsilon_{i}
$$

Where $W B$ is a measure of well-being for individuals $i$; $S$ is a measure of sports participation; $I$ is a measure of income; and $Z$ measures other variables. $\varepsilon$ is a random error term influencing subjective well-being, and the $\beta$ are coefficients to be estimated. From equation (1) the standard microeconomic concept of the marginal rate of substitution of sport and leisure can be written as in equation 2 .

$$
-\frac{d I_{i}}{d S_{i}}=\frac{\partial W B_{i} / \partial S_{i}}{\partial W B_{i} / \partial I_{i}}=\frac{\beta_{2}}{\beta_{3}}
$$

Equation 2 represents how much income would need to increase to compensate for a decrease in sports participation, but leave overall well-being unchanged or, vice versa, how much income would have to decrease to fund an equivalent increase in well-being from further sports participation, leaving overall well-being unchanged. The marginal rate of substitution can be viewed as a valuation of the well-being associated with marginal 
variations in sports participation evaluated in monetary terms. It follows that this value can be calculated by estimates of the respective coefficients $\beta_{2}$ and $\beta_{3 .}{ }^{6}$

\subsection{Data}

To estimate these coefficients, the data drawn upon in this study is the Taking Part Survey (TPS), commissioned by the Department for Culture, Media and Sport (DCMS). The TPS is a continuous repeated cross sectional national survey of sports, cultural, heritage, media and other activities for England and was first undertaken in 2005.7 In this study, data from the third wave from $2007-08$ is used and it contains 25,720 observations. ${ }^{8}$ After the removal of missing values across the set of dependent and independent variables, this sample reduced to 15,464 observations. However, further cases were removed in the light of the dependent variables containing large outliers. ${ }^{9}$ The operational sample was thus 14,913 observations. Table 1 provides a definition and summary statistics for the variables, with means reported to indicate sample proportions for binary variables for ease.

\section{INSERT TABLE 1 HERE}

As indicated in Table 1, subjective well-being is measured by a 10 point happiness scale. The most important independent variables are then a series of three variables measuring the total

\footnotetext{
${ }^{6}$ In some formulations, the log of income is analysed (for example, CASE, 2010). In the current context this is not undertaken in part because the measurement of income is based on the mid-point of income bands. It is thus less heavily skewed than data collated at the true individual level. The log of income was also insignificant in the analysis. Such a measurement of income in the Taking Part data does add some uncertainty to the analysis, but the advantage of using this data is that it allows for a detailed analysis of the types of intensity of active leisure. ${ }^{7}$ It is not a panel survey.

8 This wave is the most recent to include a variable that measures access to sports facilities. As discussed in the next section this is an important instrumental variable for the empirical analysis.

${ }^{9}$ For example, based on the sample of 15,464 observations, the maximum value of total minutes of sports participation in the last four weeks could be greater than possible given the number of days. Such errors at the upper end of the dependent variable are also noted for this data set in a different context in Dawson and Downward (2011) and probably reflect (perhaps compounded) overstatement or coding errors of the variables that comprise the components of the minutes of participation in sport. For example the largest response in the data comprised continuous sports participation of almost 72 days in a period of four weeks. A thin tail of such extreme values was thus trimmed from the data.
} 
minutes of active leisure through sport undertaken over the last four weeks. These variables were calculated as follows. The variable 'Anysport' measures the total minutes of sports activity undertaken in the four weeks prior to the interview for the survey. This was obtained by calculating the product of three variables capturing aspects of sports participation for each of 67 sports activities over the last four weeks before the survey. The variables include a binary variable measuring if the respondent participated in the activity or not in the last four weeks prior to the interview, a variable measuring the number of days on which this took place, and a variable measuring the typical number of minutes over which a session of the activity is undertaken. If the participation or not variable is coded as ' 1 ' for yes, and ' 0 ' for no, then the product of these variables gives the total minutes of participation over the four week period prior to the survey.

In order to assess the relative value of the well-being derived from sports activity that has health benefits or not, two additional sports participation variables were calculated, based on a modification of the above variable. In this respect an additional dummy variable in the data captured if the activity raised the respondent's breathing rate and, if so, identified if the activity was of moderate intensity. Coupled with information on the frequency of participation for each activity it was then possible to identify if a respondent participated in at least 30 minutes of moderate intensity activity 3 times a week for each sport. Based on these modified frequencies this then allowed the calculation of the total minutes of participation of this intensity for each sportm and thus total minutes for all sports as the variable ' $3 \times 30$ minutes' following the procedure identified above. This indicates the minutes of activity that would have health benefits as suggested in policy guidelines. A final variable was then similarly calculated as 'Low intensity', which measured the minutes of sports participation that did not meet this target or, more importantly, even at least 30 minutes of moderate intensity activity 
once a week. The aim of this variable was to capture low intensity levels of activity that are most likely undertaken for much more casual and recreational leisure purposes. An important point to note, however, is that the same individual could, in principle, be measured across all of these categories depending on the portfolio of sports that they might choose to undertake.

The other variables included in the analysis control for other observable influences on wellbeing as often reported in the literature as noted above as much as the data allow (see, for example, Dolan et al, 2008; Powdthavee, 2010). They include the socio-economic factors such as the sex, age and ethnicity of the individual, elements of their household including marital status, their educational status; the region in which they live, if they suffer from a long term illness, and if they undertake voluntary work. The latter two variables naturally might affect the ability to participate in sport, and complementary interests respectively (see, for example, Dawson and Downward, 2013). Income is included as it is a required to monetise the wellbeing effects of active leisure through sports participation. It is measured as the mid-point of a set of bounded possibilities capturing annual total personal income.

\subsection{Estimator}

It would be possible to estimate the coefficients from equation 1 using Ordinary Least Squares. However, the likely simultaneity between well-being and participation in active leisure such as sport needs to be accounted for, as noted in Section 1. This is because sports participation may be more likely, or possible, for those who are experiencing higher levels of well-being, which is perhaps mediated through their health. In these circumstances an Ordinary Least Squares regression will produce biased coefficients. To account for this an instrumental variable estimation is undertaken. 
This requires identifying relevant and valid instruments (Baum et al., 2003). The instruments should be related more to the endogenous 'regressor', which in this case are the measures of sports participation, but not directly to well-being. This will ensure that the resulting estimates are based on the statistical independence of the set of independent variables, including the instrumental variables, and the error term of the well-being equations. ${ }^{10}$ The instruments that were used in this analysis include; a measure of sports supply, as given in table 1 as 'spclose', which is a form of instrument that has been used before in the second strand of literature noted above, and the month in which the respondent answered the survey. ${ }^{11}$ In the former case it might be expected that a measure of sports supply captures the opportunity to participate in sport, but not the decision to participate. As indicated by Dolan et al. (2014) one potential problem with this measure is that it could suffer from selection effects, in that individuals locate to an environment in which more sporting opportunities are available. This is a logical possibility, but might seem to be unlikely to be a major factor in the UK context, at least in the more aggregate setting. Migration between regions in the UK is typically small, for example ranging between approximately $1.5 \%$ to $3 \%$ across inflows and outflows with net changes of substantially less than $0.5 \%$ around the period under review. ${ }^{12}$ The TPS data used in the research also indicates a narrow variance in the proportion of

\footnotetext{
${ }^{10}$ In this way the simultaneity between the sports and well-being variables that lies unobserved in the random error term is removed.

${ }^{11}$ Another potential candidate as an instrument was the ownership and use of a car with which individuals might be better able to access opportunities to participate in sport. It is not entirely clear that this would be a better instrument, a priori, as a car could be associated with an ostentatious purchase, or at least associated with status, thereby affecting overall well-being more than just via access to sports. As discussed in the text, it is difficult to provide purely compelling theoretical arguments often with instruments. Experimentation with this instrument however, its poorer performance compared to the chosen instruments. $\mathrm{R}^{2}$ values of simple regressions of Happiness and the measures of sports participation on the different instruments were always higher for happiness than sports participation for access to a car, compared to the sports facility and monthly instruments in which the reverse was true, and the Hansen statistics also became significant at $10 \%$.

12 See for example for 2009 population estimates from Office for National Statistics (2009) and migration data from http://www.ons.gov.uk/ons/rel/migration1/internal-migration-by-local-authorities-in-england-andwales/research-series--years-ending-june-2009-to-june-2011/index.html (retrieved 16th December, 2014).
} 
respondents indicating that you can get to a sports facility or not in twenty minutes. The values range from $91.3 \%$ for London to $97.1 \%$ for the South East. Of course it is possible that for specific individuals within specific locations this might be an important issue.

A further issue to discuss is whether or not sports facilities are required for participation in lower intensity activities. It is important to remember that the construction of the variable in the Survey was to capture access to any facilities that are both inside and outside and which could be for community (i.e. casual) as well as club( i.e. more organized and intense) use. ${ }^{13}$ It remains, of course, that this variable need not be relevant for the most casual of activity, that takes place, for example in a public park. Nonethless, even with major leisure activities such as swimming, which is typically the most participated in recreational activity, access to a pool is required. So too, many fitness activities that comprise the next largest group of sports activities require access to facilities (Downward et al., 2009). Finally, the largest informal team sport activity of football is now increasingly undertaken at facilities. ${ }^{14}$ On balance it is argued that there are some sensible $a$ priori grounds for the use of a supply variable as an instrument.

The use of the month of survey as an instrument also requires careful justification. It could be expected that sports participation will vary seasonally, for example connected with the competitive season, the possibility of vacations as an activity that requires time allocation, or prevailing weather conditions, which might interrupt the playing of sport or its enjoyment. However it might also be argued that seasonal variations could affect well-being, for example through mood (Schwarz and Clore 1983). Nonethless, whilst it has been argued that seasonal

\footnotetext{
${ }^{13}$ See for example http://old.culture.gov.uk/what we do/research and statistics/7387.aspx (retrieved 16th December 2014).

${ }^{14}$ See for example, http://www.thefa.com/my-football/player/5-a-side-and-futsal (retrieved 16th December, 2014)
} 
variation in the weather can affect well-being, Diener et al. (2013) argue that this is usually based on very small-scale data, and that in large-scale data the impacts are very small. It follows that it might be expected that the impact of this instrument is more likely to be greater on sports participation than well-being in this large-scale data analysis. It should be noted in this regard that the TPS is a rolling monthly survey in which similar strata and weighting as for the overall sample is targeted each month. In this way it is expected that no systematic sampling biases might be present by the use of this instrument.

Taking into account the above discussion, and as is the case with all instruments, a degree of theoretical contention exists in trying to select relevant variables. It is important therefore, that the reliability and validity of the instruments are also examined empirically by exploring the significance of the instruments in the first stage regressions and then examining if the set of regressors are orthogonal to the errors by reference to the Hansen J statistic. This analysis is presented in the next section and supports the use of these instruments. To close this section it should be noted that whilst the two-stage least squares (2SLS) estimator is the most efficient IV estimator if the errors are homoscedastic. With large scale cross-sectional data in which heteroscedasticity is likely, the generalized methods of moments (GMM) estimator is more efficient and produces heteroscedasticity consistent standard errors (see Wooldridge, 2010). This estimator is consequently used.

\section{Results}

The first set of results are presented in table 2 in which the individual significance of the instruments in the analysis can be assessed for each potentially endogenous regressor of sports participation. The table reveals that the t-test on the sports facility instrumental 
variable is significant and with large effects in all cases. The t-ratios also reveal that for 'Anysport' and 'Low intensity' sport there are distinct dips in the minutes of participation during winter, indicating a seasonal pattern. This is not the case for ' $3 \times 30$ minutes' participation, which by implication captures more committed activity. Nonetheless, negative winter month signs are observed for this variable and, as indicated in Table 3 which summarises the impact of the instruments, the F-test on the set of monthly instrumental variables allows for the rejection of the null hypothesis that they do not affect sports participation across all of the measures of sports participation. Most importantly, the Hansen J test, moreover, reveals that the null hypothesis that the instruments are unrelated to the error term of the well-being equation can be accepted at traditional levels of significance. Based on these insights it can be argued that the instrumental variable analysis has some validity and the analysis can offer some useful causal insight.

\section{INSERT TABLE 2 AND 3 HERE}

Table 4 presents the results of the instrumental variable regression analysis. The results are broadly consistent with the well-being literature, in that a quadratic age effect is identified, with initial decline in well-being. Being married or at least having other adults in the household raises well-being, compared to being widowed. The results also indicate that being of white or other ethnicities is associated with greater well-being than being Asian or of other ethnicity. It is also the case that having a long-term illness reduces well-being. The results also suggest that females generally experience higher levels of well-being compared to males and, of most importance for this analysis, that both sports participation and income raise wellbeing. In the case of 'Anysport' and 'low intensity' sport, the significance level is at the $10 \%$ 
level, but crucially the actual p-values of 0.061 and 0.056 respectively suggest that these are not particularly marginal effects and worthy of investigation. ${ }^{15}$

\section{INSERT TABLE 4 HERE}

Based on these results it is possible to calculate the marginal rates of substitution as implied in equation 2. Results are presented in the second column of Table 5.

\section{INSERT TABLE 5 HERE}

The results suggest high subjective valuations placed on a minutes sports activity generally, but exceptionally so for that which is of health giving intensity. ${ }^{16}$ However, these marginal values are only part of the basis for understanding the contribution of sport to well-being. To calculate the total value of sport to a typical individual requires knowledge of the average predicted values of the total minutes of participation at these various intensities. These can be calculated from the first-stage regression results to weight for the set of characteristics of individuals. These are estimated over the whole sample. ${ }^{17}$ It might be argued that the estimation of minutes should be based only on those that participate. This would effectively treat the frequency of participation as emergent from a 'selection' effect. However, as indicated earlier, these minutes of behaviour could in principle refer to the same individual across a portfolio of activity, which is related to, but not dependent upon, the more compelling argument, that is now adopted in the literature, that the analysis of sports participation should recognise the possibility that 'zero' is part of the choice set facing individuals. This is, of course, implicit in the recoding of ordered measurements of sports participation into binary values in much of the literature noted earlier (for example, Becchetti et al., 2008;

\footnotetext{
15 Though the details are not included here, the robustness analysis below supports this claim.

16 These values are given context later in the paper.

17 This is why predicted minutes for a $3 \times 30$ minutes is less than 30 minutes
} 
Becchetti et al., 2012; Humphreys et al., 2014 and Dolan et al., 2014). In the case of continuous covariates this approach is advocated by Humphreys and Ruseski (2011) and Downward and Rasciute (2014). These zeros are, of course, an integral component of the elucidation of the effects of sport on well-being, In this regard the 'excess' zeros from the majority of instances in which there is no participation at higher intensities indicates the degree of uniqueness of such behaviour compared to the average as it contributes to well-being. The second and third columns of Table 5 indicate the predicted minutes of the different sporting behaviours and hence total estimates of the values of sport respectively to individuals

\section{Discussion}

Table 4 reveals, as consistent with economic theory, that high marginal values are typically associated with relatively scarce activity and vice versa low marginal values with more abundant activity. Overall, the balancing of these effects suggest that active leisure through sport of the least intense nature, that is not considered as reaching health guidelines but is more likely to be of a casual recreational nature, generates the highest overall well-being to the individual. In contrast, sporting activity of the most intense nature that is linked to the production of health benefits has the lowest overall value of well-being to the individual. Prima facie, therefore, there is a case for examining the priority placed on the promotion of higher intensity physical activity through sport, should maximising social welfare be the objective of policy. In contrast the research suggests that activity of a less intense level, that is likely to be for social and recreational purposes contributes more to the well-being of individuals. Of further significance to this conclusion is that it is not obvious that encouraging all individuals to undertake higher intensity activity for longer will have the desired policy effect proposed by champions of the need to increasing the intensity of physical activity in the population. This is because of the nature of preferences that lies beneath the estimated 
marginal rates of substitution. It might be expected that as more intensely practiced activities become less scarce, perhaps due to responses to public advocacy, then their marginal values will fall to individuals.

In summary, therefore, what is clear from the introduction is that there is absolutely no policy discussion of the potential welfare trade-offs facing society from encouraging greater physical activity as a means of generating health and as a means of enhancing well-being more generally. Whilst it is not denied in this paper that the health benefits from physical activity, for example through sport, are important, it remains that a clear role for government spending is to generate 'value for money'. This is particularly in a period in which public spending is under serious review. The current results suggest that further evaluation of the non-health based function of leisure including sport in society is important. It could be, as indicated by Downward and Rasciute (2011) and Becchetti et al. (2008), Becchetti et al. (2011) and Becchetti et al. (2012) for example, that the social interactions generated through leisure are more important to social welfare and should be targeted. On the other hand, as indicated by Dolan et al. (2014), it might be that such activity is just more fun. Either way these alternatives suggest a rethinking of the way in which active leisure is promoted to individuals, stressing its social and leisure role more than that connected with health.

It is important to recognise that these values are revealed from actual behaviour in the data. In that respect they are monetised equivalents to the values subjectively experienced by individuals as shadow prices and these can clearly exceed the actual values, for example, paid to participate in activities. ${ }^{18}$ Further, it is clearly important to recognise that such values are inherently contingent on the measure of well-being that is derived. Such discussions are, of

\footnotetext{
18 This would be because of the consumer surplus experienced by individuals.
} 
course, central to the OECD (2013) review of the measurement of well-being in society noted earlier. However, as Powdthavee \& van den Berg (2011) argue, although the monetary values can vary with the use of different outcome measures, the consistency of outcomes is typically clear. This is also the case, for the current paper. As a robustness check, a five-point general health scale was also used as an indicator of more narrowly focussed well-being. The total values estimated for this measure of general health were typically smaller and had much smaller differences between them. They were $£ 39,023.96, £ 37,945.27$ and $£ 33,342.75$ for 'Anysport', 'Low intensity' and ' $3 \times 30$ minutes' respectively. This compression of values is clearly consistent with health being a component of a broader concept of well-being. It remains that the value of sports participation that is not of the intensity argued to be required to generate (actual objective) health benefits is valued more highly than that which is. A further analysis was undertaken to evaluate the monetary values from ordered probit regressions. It has been argued, for example in Rasciute and Downward (2010), that wellbeing should be analysed as an ordered magnitude, though this is debated by Ferrer-iCarbonell and Frijters(2004). In this case the derived values were found to be $£ 51,201.20$, $£ 53,479.40$ and $£ 40,973.97$ for 'Anysport', 'Low intensity' and '3x30 minutes' respectively. Though generally higher estimates are obtained, the rank ordering of the well-being valuations are preserved and those for 'Low intensity' sport exceed those for ' $3 \times 30$ minutes' sport.

Finally, it should be noted that the relative scale of effects, for example of other variables, is not dissimilar to previous research. For example being married is equivalent to approximately $£ 105,000$, which is not unlike Blanchflower and Oswald's (2004) estimate of $\$ 100,000$. It should also be noted that the current research is based on one cross section. It remains, therefore, that if better longitudinal data that carried the same details of sports and physical 
activity became available, then a more thorough dynamic evaluation could take place, in which transitory from permanent effects could be distinguished (See, for example, Frijters et al., 2011).

\section{Conclusion}

This paper draws upon unique and detailed data on active leisure through sports participation, deriving from the TPS, to investigate the two related questions of; what is the value of sport, as physical activity, to individuals in society? And, is there a case to prioritise the promotion of sport practice of an intensity to generate health benefits? By providing for the first time monetary estimates of the contribution of the actual minutes of sports participation of various intensities to an individual's subjective well-being it is shown that less scarce and less intense activity is likely to have a greater overall value to individuals than more intense activity, which is scarcer. This raises challenges for current policy that seeks to prioritise the promotion of more intense activity by suggesting that there could be a trade-off to make in policy terms between health and more generally defined social welfare as indicated by economic theory. Importantly this suggests that the fun, social and relational dimension of active leisure, which has become neglected in discussion, requires revisiting. 


\section{References}

Alesina, A., Di Tella, R., and MacCulloch, R. (2004). Inequality and happiness: Are Europeans and Americans different? Journal of Public Economics, 88, 2009-2042.

Andersson, P. (2008). Happiness and health: Well-being among the self-employed, The Journal of Socio-Economics. 37: 213-236.

Bassett, D.R .Jr., Pucher, J., Buehler, R., Thompson, D.L., \& Crouter, S.E. (2008). Walking Cycling and Obesity Rates in Europe, North America, and Australia. Journal of Physical Activity and Health, 5, 795-814.

Baum, C.F., Schaffer, M.E., \& Stillman, S. (2003). Instrumental variables and GMM: Estimation and testing. The STATA Journal, 3(1), 1-31.

Bauman A, Lewicka M, \& Schöppe S. (2005). The Health Benefits of Physical Activity in Developing Countries. Geneva, World Health Organization.

Becchetti, A., Pelloni, A., \& Rossetti, F. (2008). Relational goods, sociability, and happiness. Kyklos, 61, 343-363.

Becchetti, L., Trovato, G. \& Londono Bedoya, D.A. (2011). Income, relational goods and happiness. Applied Economics, 43, 273-290.

Becchetti, L., Ricca, E.G. \& Pelloni, A. (2012). The relationship between social leisure and life satisfaction: causality and policy implications. Social Indicators Research, 108, 453-490.

Biddle, A.J.H, Goreley, T. A \& Stensel, D.J. (2004). Health-enhancing physical activity and sedentary behaviour in children and adolescents. Journal of Sports Sciences, 22, 679-701.

Blanchflower, D.G. and Oswald, A.J. (2004). Well-being over time in Britain and the USA. Journal of Public Economics, 88, 1359-1386.

Blanchflower, D.G. and Oswald, A.J. (2008a). Is well-being U-shaped over the life cycle? Social Science \& Medicine. 66: 1733-1749.

Blanchflower, D.G. and Oswald, A.J. (2008b). Hypertension and happiness across nations, Journal of Health Economics. 27(2): 218-233

British Heart Foundation National Centre (2013). Economic Costs of Physical Inactivity Evidence Briefing. Loughborough University:Loughborough.

Brown, J.L., MacDonald, R. \& Mitchell, R. (2014). Are People Who Participate in Cultural Activities More Satisfied with Life? Social Indicators Research, DOI 10.1007/s11205-0140678-7.

Bruni, L. and Stanca, L. (2006). Income Aspirations, Television and Happiness: Evidence from the World Values Survey, Kyklos. 59(2): 209-225. 
Carroll, N. Frijters, P., and Shields, M.A. (2009). Quantifying the costs of drought, new evidence from life satisfaction data, Journal of Population Economics. 22: 445-461.

Camacho, T.C., Roberts, R.E., Lazarus, N.B., Kaplan, G.A. \& Cohen, R.D. (1991). Physical activity and depression: Evidence from the Alemada county study. American Journal of Epidemiology. $134,220-231$.

CASE (2010). Understanding the value of engagement in culture and sport, technical report. https://www.gov.uk/government/uploads/system/uploads/attachment_data/file/88450/CA SE-Value-technical-report-July10.pdf (last retrieved 29th September 2014).

Cevero, R. \& Duncan, M. (2003). Walking, bicycling and urban landscapes: evidence from the San-Francisco Bay Area. American Journal of Public health, 93(9), 1478-1483.

Chalder, M., Wiles, N.J., Campbell, J., Hollinghurst, S.P., Haase, A.M., Taylor, A.H., et al. (2012). Facilitated physical activity as a treatment for depressed adults: randomised controlled trial. British Medical Journal 344, DOI: 10.1136/bmj.e2758.

Clark, A.E. \& Oswald, A. J., (2002). A simple statistical method for measuring how life events affect happiness. International Journal of Epidemiology, 31, 1139-1144.

Clark, A.E. Etile, F. Postel-Vinnay, F. Senik, C and Van der Straeten, K. (2005). Heterogeneity in reported well-being: Evidence from twelve European countries, Economic Journal. 115: C118C132.

Clark, A.E., Diener, E., Georgellis, Y. and Lucas, R.E. 2008. Lags and Leads in Life Satisfaction: A Test of the Baseline Hypothesis. Economic Journal, 118: F222-F243.

Cheng, T.C., Powdthavee, N and Oswald, A.J. (forthcoming) Longitudinal evidence for a midlife nadir in human well-being: results from four data sets, The Economic Journal, (Retrieved from http://www.powdthavee.co.uk/2.html 12/12/14)

Cook I, Alberts M, \& Lambert EV. (2008). Relationship between adiposity and pedometerassessed ambulatory activity in adult, rural African women. International Journal of Obesity, 32, 1327-1330.

Coverdill, J.E., López, C.A. and Petrie, M.A. (2011) Race, Ethnicity and the Quality of Life in America, 1972-2008, Social Forces, 89(3) 783-806

Dawson, P. and Downward, P. (2011). Participation, spectatorship and media coverage in sport: Some initial insights, in Andreff, W (ed) Contemporary Issues In sports Economics, Edward Elgar: London.

Dawson, P. \& Downward, P., (2013). The Relationship Between Participation in Sport and Sport Volunteering: An Economic Analysis. International Journal of Sport Finance, 8 (1), 75 92.

DCMS/Strategy Unit (2002). Game Plan: A strategy for delivering government's sport and physical activity objectives. London. 
Department of Health (2001). Comparative review and assessment of key health state measures of the general population.

http://eprints.soton.ac.uk/80196/1/2001_Comparative_review_of_key_health_state_measure s.pdf (last retrieved 29th September 2014).

Department of Health (2004). At least five a week: Evidence on the impact of physical activity and its relationship to health.A report from the Chief Medical Officer.

http://webarchive.nationalarchives.gov.uk/20130107105354/http://www.dh.gov.uk/en/Pu blicationsandstatistics/Publications/PublicationsPolicyAndGuidance/DH_4080994 (last retrieved 29th September 2014)

Diener, E., Inglehart, R. and Tay, L. (2013). Theory and Validity of Life Satisfaction Scales, Social Indicators Research, 112, 497-527.

Dolan, P., Peasgood, T., \& White, M. (2008). Do we really know what makes us happy? A review of the economic literature on the factors associated with subjective well-being. Journal of Economic Psychology, 29, 94-122.

Dolan, P., Metcalfe, R., and Layard, R. (2011). Measuring Subjective Well-being for Public Policy, Office for National Statistics, February.

Dolan, P., Kavetsos, G. and Vlaev, I. (2014). The Happiness Workout, Social Indicators Research, 119, 1363-1377.

Downward, P. M., A. Dawson and T. Dejonghe (2009). Sports Economics: Theory, Evidence and Policy, London, Elsevier.

Downward, P. M., \& Rasciute, S. (2011). Does Sport Make You Happy? An Analysis of the Wellbeing Derived from Sports Participation. International Review of Applied Economics, 25 (3), 331-348.

Downward, P. and Rasciute, S. (2014) Exploring the covariates of sports participation for health: An Analysis of Males and Females in England. Journal of Sports Sciences. http://dx.doi.org/10.1080/02640414.2014.924056

Farmer, M.E, Locke, B.Z., Moscicki, E.K. Dannenberg, A.L., Larson, D.B., \& Radloff, L.S. (1988) The NHANES epidemiologic follow-up study. American Journal of Epidemiology, 128, 13401351.

Ferrer-i-Carbonell, A. \& Frijters, P. (2004). How important is methodology for the estimates of the determinants of happiness. Economic Journal, 114, 641-659.

Frey, B., (2008), Happiness: A revolution in economics. Cambridge Mass., MIT Press.

Frijters, P. Hasken-DeNew, J.P, Shields, M.A. (2004). Money does matter! Evidence from increasing real income and life satisfaction in East Germany following reunification, American Economic Review. 94(3): 730-740. 
Frijters, P., Johnston, D.W., \& Shields, M.A. (2011). Happiness Dynamics with Quarterly Life Event Data. Scandinavian Journal of Economics, 113 (1), 190 - 211.

Fujiwara, D., \& Campbell, R., (2011). Valuation Techniques for Social Cost-Benefit Analysis: Stated Preference, Revealed Preference and Subjective Well-Being Approaches. Green Book Discussion Paper, London, H.M Treasury.

Gardner, J. and Oswald, A.J. 2006. Do divorcing couples become happier by breaking up. Journal of the Royal Statistical Society (A), 169 (2), 319-336.

Gill, J.M. \& Cooper, A.R. (2008). Physical Activity and Prevention of type 2 diabetes mellitus. Sports Medicine, 38, 807-824.

Global Advocacy for Physical Activity (GAPA) the Advocacy Council of the International Society for Physical Activity and Health (ISPAH). (2012). NCD Prevention: Investments that Work for Physical Activity. British Journal of Sports Medicine, 46 (8), 709-712.

Green, M. (2004). Changing Policy Priorities for Sport in England: The Emergence of Elite Sport Development as a key Policy Concern, Leisure Studies, 23, 365-385.

Green, M., \& Houlihan, B. (2005). Elite Sport Development: Policy Learning and Policy Priorities. London, Routledge..

Guven, C., Senik C., and Stichnoth, H. (2012) You can't be happier than your wife. Happiness gaps and divorce, Journal of Economic Behavior \& Organization 82, 110-130

Haskell, W.L., Lee, I.M., Pate, R.R., Powell, K.E., Blair, S.N., Franklin, B.A et al. (2007). Updated recommendation for adults from the American college of sports medicine and the American heart association. Medicine and science in sports and exercise, 39,1423-1434.

Helliwell, J.F. \& Barrington-Leigh, C.P., (2010). Measuring and understanding subjective wellbeing, NBERWorking Paper, No.15887, National Bureau of Economic Research.

Houlihan, B. (1997). Sport, Policy and Politics: A Comparative Analysis, London, Routledge.

Huang, H. \& Humphreys, B., (2010). Sports Participation and Happiness: Evidence from U.S. Micro Data, Journal of Economic Psychology, 33(4), 776-793.

Humphreys, B.R. \& Ruseski, J.E. (2011). Economic Analysis of Participation and Time Spent in Physical Activity. B.E. Journal of Economic Analysis \& Policy, (Contributions)1, 1-47.

Humphreys, B. R., L. McLeod, \& J. E. Ruseski (2014). Physical Activity and Health Outcomes: Evidence from Canada, Health Economics, 23, 33-54.

Kahneman, D., (1999). Objective happiness, in Kahneman, D., Diener, E. \& Schwarz, N.,(Eds.), Well-being: Foundations of hedonic psychology. NewYork, Russell Sage Foundation Press. 
Krogh J., Nordentoft, M., Sterne, J.A.C., \& Lawlor, D.A. (2011) The effect of exercise in clinically depressed adults: systematic review and meta-analysis of randomized controlled trials. Journal of Clinical Psychiatry, 72, 529-38.

Lechner M (2009). Long-run labour market and health effects of individual sports activities, Journal of Health Economics, 28(4), 839-854.

Ljungqvist, A., Jenoure, P., Engebretsen, L., Alonso, J.M., Bahr, R., Clough, A., De Bondt, G. et al. (2009). The International Olympic Committee (IOC) Consensus Statement on periodic health evaluation of elite athletes. British Journal of Sports Medicine, 43 (9), 631-643.

Lucas, R.E., Clark, A.E., Georgellis, Y. Y. and Diener, E. (2003). Re-examining adaptation and the set point model of happiness: reactions to changes in marital status. Journal of Personality and Social Psychology, 84, 527-539.

Marshall, S.W., \& Guskiewicz, K.M. (2003). Sports and recreational injury: the hidden cost of a healthy lifestyle. Injury Prevention, 9, 100-102.

Mead, G.E., Morley, W., Campbell, P., Greig, C.A., McMurdo, M., \& Lawlor, D.A. (2009). Exercise for depression. Cochrane Database Systematic Review, 3, CD004366.

O'Donovan, G., Blazevich, A.J., Boreham, C., Cooper, A.R, Crank, H., Ekelund, U., et al. (2010). The ABC of Physical Activity for Health: A consensus statement from the British Association of Sport and Exercise Sciences. Journal of Sports Sciences, 28, 573-591.

OECD (2013). OECD Guidelines on Measuring Subjective Well-being. OECD Publishing. http://www.oecd-ilibrary.org/economics/oecd-guidelines-on-measuring-subjective-wellbeing_9789264191655-en (last retrieved 29th September 2014).

Office for National Statistics (2009) Population trends, Winter, No 138.

Oja, P. Vuori, I \& Paronen, O. (1998). Daily walking and cycling to work: their utility as healthenhancing physical activity. Patient Education and Counselling, 33, S87-S94.

Oswald, A.J. (1997). Happiness and Economic Performance. Economic Journal, 107, 18151831.

Pate, R.R., Pratt, M. Blair, S.N., Haskell, W.L., Macera, C.A. \& Bouchard, C. (1995). Physical activity and public health: A recommendation from the Centers for Disease Control and Prevention and the American College of Sports Medicine. Journal of the American Medical Association, 275, (5), 402-407.

Pawlowski, T., Downward, P., \& Rasciute, S. (2011). Subjective well-being in European countries - On the age specific impact of physical activity. European Review of Aging and Physical Activity, 8, 93-102

Powdthavee, N. (2010). The Happiness Equation: The Surprising Economics of Our Most Valuable Asset. Icon Books, UK. 
Powdthavee, N. \& van den Berg, B. (2011). Putting Different Price Tags on the Same Health Condition: Re-evaluating the Well-Being Valuation Approach. Journal of Health Economics, 30(5), 1032-1043.

Rasciute. S., \& Downward, P.M., (2010). Health or happiness? What is the impact of physical activity on the individual. Kyklos, 63(2),256-270

Sarma, S., Devlin, R.A., Gilliland, J., Karen Campbell, M. and Zaric, G.S. (2014). The effect of Leisure-Time physical activity on Obesity, Diabetes, High B.P. and Heart Disease among Canadians: Evidence from 2000/2001 to 2005/2006, Health Economics, published online: 23 SEP 2014 DOI: 10.1002/hec.3106

Schwarz, N., and Clore, G. L. (1983). Mood, misattribution, and judgments of well-being: Informative and directive functions of affective states. Journal of Personality and Social Psychology, 45, 513-523.

Shephard, R.J. (2008). Is Active Commuting the answer to Population Health? Sports Medicine, 38(9), 751-758.

Smith, A. \& Bird, S. (2004). From evidence to policy: reflections on emerging themes in healthrelated physical activity. Journal of Sports Sciences, 22, 791-799.

Sport England (2013) A Summary of Sports participation Indicators, Retrieved from http://www.sportengland.org/media/112857/summary-of-sport-participationindicators.pdf (last retrieved 29th September 2014).

Stiglitz, J.E., Sen, A. \& Fitoussi, J.P. (2008) Report by the Commission on the Measurement of Economic Performance and Social Progress. www.stiglitz-sen-

fitoussi.fr/documents/rapport_anglais.pdf (last retrieved 29th September 2014).

Sugden, R., (2005). Correspondence of Sentiments: An Explanation of the Pleasure of Social Interaction, in Bruni, L., \& Porta, P.L., (Eds) Economics and Happiness: Framing the Analysis. Oxford, Oxford University Press.

Stutzer, A. and Frey, B.S. (2006). Does marriage make people happy, or do happy people get married? The Journal of Socio-Economics, 35, 326-347.

Thoits, P. A., and Hewitt, L. N. (2001). Volunteering work and well-being. Journal of Health and Social Behaviour, 42, 115-131.

Waldron, S. (2010). Measuring Subjective Wellbeing in the UK, Office for National Statistics Working Paper, September,

Warburton, D.E.R., Nicol, C.W., \& Bredin, S.S.D. (2006). Health benefits of physical activity: the evidence, Canadian Medical Association Journal, 174(6), 801-809. 
Welsch, H. (2008). The Social Costs of Civil Conflict: Evidence from Surveys of Happiness, Kyklos. 61(2): 320-340.

WHO (2004). Global Strategy on Diet, Physical Activity and Health.

http://www.who.int/dietphysicalactivity/strategy/eb11344/strategy_english_web.pdf (last retrieved 29th September 2014)

WHO (2010) Global recommendations on physical activity for health, Retrieved from http://www.who.int/dietphysicalactivity/publications/9789241599979/en/index.html. (last retrieved 29th September 2014).

Winkelmann, L and Winkelmann, R. (1998). Why are the unemployed so unhappy? Evidence from Panel Data, Economica. 65(257): 1-15

Wooldridge, J. M. (2010). Econometric analyses of cross section and panel data (2nd Ed.). Cambridge, Mass. \& London: MIT Press. 
Table 1. Variable Definitions and Descriptive Statistics

\begin{tabular}{|c|c|c|c|}
\hline $\begin{array}{c}\text { Dependent Variables } \\
\text { happy } \\
\text { Independent Variables }\end{array}$ & $\begin{array}{l}\text { Definition } \\
\text { Taking all things together, how happy would you say you are? '1' - Extremely unhappy to '10' Extremely happy }\end{array}$ & $\begin{array}{l}\text { Mean } \\
7.750\end{array}$ & $\begin{array}{l}\text { Std. Dev. } \\
1.667\end{array}$ \\
\hline Anysport & Total Minutes of sports participation & 412.882 & 642.249 \\
\hline Low intensity & Total Minutes of sports participation of less than once a week at moderate intensity & 334.129 & 533.332 \\
\hline $3 \times 30$ minutes & Total Minutes of sports participation of 3 or more times a week at moderate intensity & 29.319 & 81.732 \\
\hline married & Married ' 1 ' or not ' 0 ' & 0.468 & 0.499 \\
\hline single & Single ' 1 ' or not '0' & 0.340 & 0.474 \\
\hline widow & Widowed '1' or not '0' & 0.055 & 0.229 \\
\hline separated & Separated ' 1 ' or not ' 0 ' & 0.137 & 0.344 \\
\hline he & Higher education ' 1 ' or not ' 0 ' & 0.433 & 0.496 \\
\hline Alevel & A Levels or equivalent ' 1 ' or not ' 0 ' & 0.196 & 0.397 \\
\hline Apprentice & Apprenticeship ' 1 ' or not '0' & 0.051 & 0.221 \\
\hline othered & Other education ' 1 ' or not ' 0 ' & 0.320 & 0.466 \\
\hline Working & Working ' 1 ' or not ' 0 ' & 0.647 & 0.478 \\
\hline Student & Student ' 1 ' or not ' 0 ' & 0.033 & 0.178 \\
\hline Keephouse & Keeps house ' 1 ' or not ' 0 ' & 0.067 & 0.250 \\
\hline Retired & Retired '1' or not '0' & 0.164 & 0.370 \\
\hline otherwork & Other workstatus ' 1 ' or not ' 0 ' & 0.089 & 0.285 \\
\hline Numadults & Number of adults in the household & 1.968 & 0.852 \\
\hline Numchild & Number of children in the household & 0.623 & 0.975 \\
\hline sex & Male ' 1 ' or Female ' 0 ' & 0.448 & 0.497 \\
\hline age & Age in years & 44.351 & 16.528 \\
\hline White & White British ' 1 ' or not ' 0 ' & 0.884 & 0.320 \\
\hline Asian & Asian '1' or not '0' & 0.064 & 0.244 \\
\hline Black & Black '1' or not '0' & 0.036 & 0.185 \\
\hline Othereth & Other ethnicity ' 1 ' or not '0' & 0.017 & 0.128 \\
\hline Income & Individual income '£000s' & 18.778 & 14.300 \\
\hline NorthE & North East '1' or not '0' & 0.092 & 0.290 \\
\hline
\end{tabular}


Table 1. Continued

\begin{tabular}{|c|c|c|c|}
\hline NorthW & NorthWest '1' or not '0' & 0.106 & 0308 \\
\hline Yorks & Yorkshire and Humberside ' 1 ' or not '0' & 0.100 & 0.300 \\
\hline EMid & East Midlands ' 1 ' or not '0' & 0.096 & 0.294 \\
\hline East & East of England ' 1 ' or not '0' & 0.108 & 0.310 \\
\hline SouthE & South East ' 1 ' or not '0' & 0.143 & 0.350 \\
\hline SouthW & South West' 1 ' or not ' 0 ' & 0.118 & 0.322 \\
\hline London* & London '1' or not '0' & 0.128 & 0.334 \\
\hline lillharm & Long-standing illness ' 1 ' or not '0' & 0.254 & 0.436 \\
\hline volwork & Undertaken voluntary work or not in the last 12 months ' 1 ' or not ' 0 ' & 0.275 & 0.447 \\
\hline Instrumental Variables & & 0.014 & 0.117 \\
\hline July 2007 & Surveyed in July 2007 '1' or not '0' & 0.078 & 0.268 \\
\hline August 2007 & Surveyed in August 2007 ' 1 ' or not '0' & 0.096 & 0.294 \\
\hline September 2007 & Surveyed in September 2007 '1' or not '0' & 0.096 & 0.295 \\
\hline November 2007 & Surveyed in November 2007 '1' or not '0' & 0.068 & 0.252 \\
\hline December 2007 & Surveyed in December 2007 '1' or not '0' & 0.104 & 0.305 \\
\hline January 2008 & Surveyed in January 2008 ' 1 ' or not '0' & 0.066 & 0.249 \\
\hline February 2008 & Surveyed in February 2008 '1' or not '0' & 0.080 & 0.271 \\
\hline March 2008 & Surveyed in March 2008 '1' or not '0' & 0.096 & 0.295 \\
\hline April 2008 & Surveyed in April 2008 '1' or not '0' & 0.074 & 0.262 \\
\hline May 2008 & Surveyed in May 2008 '1' or not '0' & 0.066 & 0.248 \\
\hline June 2008 & Surveyed in June 2008 ' 1 ' or not '0' & 0.039 & 0.193 \\
\hline July 2008 & Surveyed in July 2008 '1' or not '0' & 0.016 & 0.126 \\
\hline August 2008 & Surveyed in August 2008 ' 1 ' or not '0' & & \\
\hline spclose & You can get to a sports facility within 20 minutes ' 1 ' or not '0' & 0.949 & 0.220 \\
\hline $\mathrm{n}$ & & 14,913 & \\
\hline
\end{tabular}


Table 2. First Stage Regression Estimates

\begin{tabular}{|c|c|c|c|}
\hline & Anysport & Low intensity & $3 \times 30$ minutes \\
\hline married & $\begin{array}{l}-8.518 \\
(-0.55)\end{array}$ & $\begin{array}{l}-1.894 \\
(-0.14)\end{array}$ & $\begin{array}{l}-2.506 \\
(-1.32)\end{array}$ \\
\hline \multirow{2}{*}{ single } & 10.82 & 11.23 & 0.0484 \\
\hline & $(0.63)$ & $(0.78)$ & $(0.02)$ \\
\hline \multirow[t]{2}{*}{ widow } & 17.00 & 5.992 & $5.411^{*}$ \\
\hline & $(0.74)$ & $(0.30)$ & (1.83) \\
\hline \multirow[t]{2}{*}{ he } & $56.67^{* *}$ & $34.36^{* *}$ & $9.293^{* *}$ \\
\hline & $(4.58)$ & $(3.30)$ & $(5.98)$ \\
\hline \multirow[t]{2}{*}{ Alevel } & $24.50^{*}$ & 19.76 & 1.010 \\
\hline & $(1.70)$ & $(1.62)$ & $(0.57)$ \\
\hline \multirow[t]{2}{*}{ Apprentice } & 0.170 & 9.665 & $-6.031^{* *}$ \\
\hline & $(0.01)$ & $(0.44)$ & $(-2.40)$ \\
\hline \multirow[t]{2}{*}{ Working } & 0.0996 & -2.117 & -0.910 \\
\hline & $(0.01)$ & $(-0.13)$ & $(-0.37)$ \\
\hline \multirow[t]{2}{*}{ Student } & $78.87^{* *}$ & 37.59 & $15.75^{* *}$ \\
\hline & $(2.03)$ & (1.21) & $(2.58)$ \\
\hline \multirow[t]{2}{*}{ Keephouse } & -21.92 & -15.27 & -3.877 \\
\hline & $(-0.88)$ & $(-0.72)$ & $(-1.39)$ \\
\hline \multirow[t]{2}{*}{ Retired } & $106.2^{* *}$ & $78.66^{* *}$ & $9.243^{* *}$ \\
\hline & $(4.12)$ & $(3.56)$ & $(3.10)$ \\
\hline \multirow[t]{2}{*}{ Numadults } & 9.878 & 8.298 & 0.352 \\
\hline & $(1.34)$ & $(1.36)$ & $(0.34)$ \\
\hline \multirow[t]{2}{*}{ Numchild } & $-32.15^{* *}$ & $-23.58^{* *}$ & $-4.179^{* *}$ \\
\hline & $(-5.51)$ & $(-4.87)$ & $(-5.53)$ \\
\hline \multirow[t]{2}{*}{ sex } & $207.2^{* *}$ & $164.5^{* *}$ & $15.80^{* *}$ \\
\hline & $(18.00)$ & (17.15) & (10.17) \\
\hline \multirow[t]{2}{*}{ age } & $-12.66^{* *}$ & $-9.080^{* *}$ & $-1.512^{* *}$ \\
\hline & $(-6.49)$ & $(-5.56)$ & $(-5.93)$ \\
\hline \multirow[t]{2}{*}{ agesq } & $0.0399^{* *}$ & $0.0277^{*}$ & $0.00552^{* *}$ \\
\hline & $(2.01)$ & (1.65) & $(2.25)$ \\
\hline \multirow[t]{2}{*}{ white } & -20.96 & -23.12 & -1.063 \\
\hline & $(-0.52)$ & $(-0.69)$ & $(-0.22)$ \\
\hline \multirow[t]{2}{*}{ Asian } & $-86.35^{*}$ & $-68.38^{*}$ & $-8.911^{*}$ \\
\hline & $(-1.94)$ & $(-1.84)$ & $(-1.66)$ \\
\hline \multirow[t]{2}{*}{ Black } & $-85.99^{*}$ & $-75.08^{*}$ & -8.535 \\
\hline & $(-1.83)$ & $(-1.93)$ & $(-1.44)$ \\
\hline \multirow[t]{2}{*}{ income } & $3.223^{* *}$ & $2.459^{* *}$ & $0.302^{* *}$ \\
\hline & (7.04) & (6.41) & $(5.05)$ \\
\hline \multirow[t]{2}{*}{ NorthE } & $94.18^{* *}$ & $78.89^{* *}$ & 4.718 \\
\hline & $(4.04)$ & $(4.00)$ & (1.61) \\
\hline \multirow[t]{2}{*}{ NorthW } & $91.09^{* *}$ & $67.60^{* *}$ & $8.888^{* *}$ \\
\hline & $(4.23)$ & (3.78) & $(2.95)$ \\
\hline \multirow[t]{2}{*}{ Yorks } & $69.07^{* *}$ & $56.84^{* *}$ & 4.601 \\
\hline & (3.18) & (3.11) & $(1.60)$ \\
\hline \multirow[t]{2}{*}{ EMid } & $89.69^{* *}$ & $79.89^{* *}$ & 1.523 \\
\hline & $(4.02)$ & $(4.21)$ & $(0.55)$ \\
\hline WMid & $72.51^{* *}$ & $57.36^{* *}$ & $5.487^{*}$ \\
\hline & $(3.47)$ & (3.28) & (1.93) \\
\hline
\end{tabular}


Table 2. Continued

\begin{tabular}{|c|c|c|c|}
\hline & Anysport & Low intensity & $3 \times 30$ minutes \\
\hline East & $\begin{array}{l}79.34^{* *} \\
(3.75)\end{array}$ & $\begin{array}{l}66.13^{* *} \\
(3.71)\end{array}$ & $\begin{array}{l}3.671 \\
(1.34)\end{array}$ \\
\hline SouthE & $\begin{array}{l}82.71^{* *} \\
(4.09)\end{array}$ & $\begin{array}{l}69.11^{* *} \\
(4.08)\end{array}$ & $\begin{array}{l}3.335 \\
(1.23)\end{array}$ \\
\hline SouthW & $\begin{array}{l}70.66^{* *} \\
(3.36)\end{array}$ & $\begin{array}{l}51.53^{* *} \\
(2.94)\end{array}$ & $\begin{array}{l}6.557^{* *} \\
(2.29)\end{array}$ \\
\hline lillharm & $\begin{array}{c}-71.21^{* *} \\
(-5.88)\end{array}$ & $\begin{array}{c}-48.71^{* *} \\
(-4.67)\end{array}$ & $\begin{array}{c}-9.546^{* *} \\
(-6.96)\end{array}$ \\
\hline volwork & $\begin{array}{l}102.6^{* *} \\
(8.66)\end{array}$ & $\begin{array}{l}71.20^{* *} \\
(7.23)\end{array}$ & $\begin{array}{l}13.16^{* *} \\
(7.94)\end{array}$ \\
\hline July07 & $\begin{array}{l}-86.41 \\
(-1.54)\end{array}$ & $\begin{array}{l}-77.79 \\
(-1.62)\end{array}$ & $\begin{array}{l}-5.352 \\
(-0.80)\end{array}$ \\
\hline Aug07 & $\begin{array}{l}-28.40 \\
(-0.66)\end{array}$ & $\begin{array}{l}-27.16 \\
(-0.74)\end{array}$ & $\begin{array}{l}0.389 \\
(0.08)\end{array}$ \\
\hline Sep07 & $\begin{array}{l}-22.15 \\
(-0.53)\end{array}$ & $\begin{array}{l}-31.34 \\
(-0.88)\end{array}$ & $\begin{array}{l}3.935 \\
(0.76)\end{array}$ \\
\hline Oct07 & $\begin{array}{l}-36.58 \\
(-0.87)\end{array}$ & $\begin{array}{l}-38.41 \\
(-1.08)\end{array}$ & $\begin{array}{l}3.255 \\
(0.64)\end{array}$ \\
\hline Nov07 & $\begin{array}{c}-132.4^{* *} \\
(-3.24)\end{array}$ & $\begin{array}{l}-112.8^{* *} \\
(-3.24)\end{array}$ & $\begin{array}{l}-6.834 \\
(-1.41)\end{array}$ \\
\hline Dec07 & $\begin{array}{c}-131.2^{* *} \\
(-3.11)\end{array}$ & $\begin{array}{c}-113.7^{* *} \\
(-3.17)\end{array}$ & $\begin{array}{l}-6.056 \\
(-1.20)\end{array}$ \\
\hline Jan08 & $\begin{array}{c}-118.6^{* *} \\
(-2.88)\end{array}$ & $\begin{array}{l}-102.0^{* *} \\
(-2.91)\end{array}$ & $\begin{array}{l}-4.477 \\
(-0.91)\end{array}$ \\
\hline Feb08 & $\begin{array}{c}-88.80^{* *} \\
(-2.07)\end{array}$ & $\begin{array}{c}-80.98^{* *} \\
(-2.23)\end{array}$ & $\begin{array}{l}-0.567 \\
(-0.11)\end{array}$ \\
\hline Mar08 & $\begin{array}{l}-30.71 \\
(-0.72)\end{array}$ & $\begin{array}{l}-31.28 \\
(-0.86)\end{array}$ & $\begin{array}{l}2.421 \\
(0.47)\end{array}$ \\
\hline Apr08 & $\begin{array}{l}-49.62 \\
(-1.19)\end{array}$ & $\begin{array}{l}-51.30 \\
(-1.45)\end{array}$ & $\begin{array}{l}3.418 \\
(0.66)\end{array}$ \\
\hline May08 & $\begin{array}{l}-69.83^{*} \\
(-1.65)\end{array}$ & $\begin{array}{l}-66.23^{*} \\
(-1.85)\end{array}$ & $\begin{array}{l}0.844 \\
(0.17)\end{array}$ \\
\hline June08 & $\begin{array}{l}-42.00 \\
(-0.96)\end{array}$ & $\begin{array}{l}-38.67 \\
(-1.04)\end{array}$ & $\begin{array}{l}2.595 \\
(0.50)\end{array}$ \\
\hline July08 & $\begin{array}{l}-62.20 \\
(-1.36)\end{array}$ & $\begin{array}{l}-59.80 \\
(-1.54)\end{array}$ & $\begin{array}{l}0.675 \\
(0.12)\end{array}$ \\
\hline spclose & $\begin{array}{l}80.41^{* *} \\
(4.03)\end{array}$ & $\begin{array}{l}60.58^{* *} \\
(3.54)\end{array}$ & $\begin{array}{l}8.754^{* *} \\
(3.90)\end{array}$ \\
\hline constant & $\begin{array}{l}621.8^{* *} \\
(7.68)\end{array}$ & $\begin{array}{l}487.5^{* *} \\
(7.21)\end{array}$ & $\begin{array}{l}57.20^{* *} \\
(5.67)\end{array}$ \\
\hline $\mathrm{n}$ & 14,913 & 14,913 & 14,913 \\
\hline $\mathrm{R}^{2}$ & 0.0942 & 0.0763 & 0.0657 \\
\hline$F(43,14,869)$ & 34.30 & 28.43 & 18.95 \\
\hline Prob $>$ F & 0.000 & 0.000 & 0.000 \\
\hline
\end{tabular}


Table 3. Assessment of Instruments

\begin{tabular}{c|ccc} 
Endogenous variable & Anysport & Low intensity & $3 \times 30$ minutes \\
\hline \hline spclose & & & \\
$\mathrm{t}(14,877)$ & 4.03 & 3.54 & 3.90 \\
$\mathrm{P}>\mathrm{t}$ & 0.000 & 0.000 & 0.000 \\
Monthly Variables & & & \\
$\mathrm{F}(13,14,869)$ & 5.50 & 4.85 & 3.03 \\
$\mathrm{P}>\mathrm{F}$ & 0.000 & 0.000 & 0.000 \\
Hansen J Test & & & \\
$\chi^{2}(12)$ & 16.6279 & 16.3755 & 15.3238 \\
$\mathrm{P}>\mathrm{x}$ & 0.1641 & 0.1746 & 0.2242 \\
\hline
\end{tabular}


Table 4. IV Regression Estimates

\begin{tabular}{|c|c|c|c|}
\hline & happy & happy & happy \\
\hline Anysport & $\begin{array}{c}0.000570^{*} \\
(1.88)\end{array}$ & $\mathrm{n} / \mathrm{a}$ & $\mathrm{n} / \mathrm{a}$ \\
\hline Low intensity & $\mathrm{n} / \mathrm{a}$ & $\begin{array}{c}0.000740^{*} \\
(1.91)\end{array}$ & $\mathrm{n} / \mathrm{a}$ \\
\hline $3 \times 30$ minutes & $\mathrm{n} / \mathrm{a}$ & $\mathrm{n} / \mathrm{a}$ & $\begin{array}{c}0.00650^{* *} \\
(2.00)\end{array}$ \\
\hline married & $\begin{array}{l}0.544^{* *} \\
(11.57)\end{array}$ & $\begin{array}{l}0.541^{* *} \\
(11.50)\end{array}$ & $\begin{array}{l}0.554^{* *} \\
(11.40)\end{array}$ \\
\hline single & $\begin{array}{c}-0.0313 \\
(-0.59)\end{array}$ & $\begin{array}{c}-0.0333 \\
(-0.63)\end{array}$ & $\begin{array}{c}-0.0274 \\
(-0.51)\end{array}$ \\
\hline widow & $\begin{array}{c}-0.278^{* *} \\
(-3.42)\end{array}$ & $\begin{array}{c}-0.272^{* *} \\
(-3.35)\end{array}$ & $\begin{array}{c}-0.305^{* *} \\
(-3.65)\end{array}$ \\
\hline he & $\begin{array}{c}-0.0224 \\
(-0.58)\end{array}$ & $\begin{array}{c}-0.0155 \\
(-0.42)\end{array}$ & $\begin{array}{c}-0.0511 \\
(-1.09)\end{array}$ \\
\hline Alevel & $\begin{array}{c}-0.00441 \\
(-0.11)\end{array}$ & $\begin{array}{c}-0.00505 \\
(-0.12)\end{array}$ & $\begin{array}{c}0.00263 \\
(0.06)\end{array}$ \\
\hline Apprentice & $\begin{array}{l}0.147^{*} \\
(2.22)\end{array}$ & $\begin{array}{l}0.140^{* *} \\
(2.10)\end{array}$ & $\begin{array}{l}0.184^{* *} \\
(2.64)\end{array}$ \\
\hline Working & $\begin{array}{l}0.528^{* *} \\
(9.06)\end{array}$ & $\begin{array}{l}0.530^{* *} \\
(9.05)\end{array}$ & $\begin{array}{l}0.533^{* *} \\
(8.97)\end{array}$ \\
\hline Student & $\begin{array}{l}0.550^{* *} \\
(5.80)\end{array}$ & $\begin{array}{l}0.567^{* *} \\
(6.07)\end{array}$ & $\begin{array}{l}0.493^{* *} \\
(4.51)\end{array}$ \\
\hline Keephouse & $\begin{array}{l}0.496^{* *} \\
(6.08)\end{array}$ & $\begin{array}{l}0.494^{* *} \\
(6.04)\end{array}$ & $\begin{array}{l}0.507^{* *} \\
(6.13)\end{array}$ \\
\hline Retired & $\begin{array}{l}0.732^{* *} \\
(8.77)\end{array}$ & $\begin{array}{l}0.734^{* *} \\
(8.82)\end{array}$ & $\begin{array}{l}0.735^{* *} \\
(8.77)\end{array}$ \\
\hline Numadults & $\begin{array}{l}0.123^{* *} \\
(6.58)\end{array}$ & $\begin{array}{l}0.122^{* *} \\
(6.51)\end{array}$ & $\begin{array}{l}0.127^{* *} \\
(6.60)\end{array}$ \\
\hline Numchild & $\begin{array}{c}0.00233 \\
(0.12)\end{array}$ & $\begin{array}{c}0.00147 \\
(0.08)\end{array}$ & $\begin{array}{c}0.0110 \\
(0.52)\end{array}$ \\
\hline sex & $\begin{array}{c}-0.244^{* *} \\
(-3.51)\end{array}$ & $\begin{array}{c}-0.247^{* *} \\
(-3.53)\end{array}$ & $\begin{array}{c}-0.229^{* *} \\
(-3.83)\end{array}$ \\
\hline age & $\begin{array}{c}-0.0396^{* *} \\
(-5.80)\end{array}$ & $\begin{array}{c}-0.0401^{* *} \\
(-6.02)\end{array}$ & $\begin{array}{c}-0.0370^{* *} \\
(-4.88)\end{array}$ \\
\hline agesq & $\begin{array}{c}0.000479^{* *} \\
(7.75)\end{array}$ & $\begin{array}{c}0.000482^{* *} \\
(7.80)\end{array}$ & $\begin{array}{c}0.000466^{* *} \\
(7.22)\end{array}$ \\
\hline white & $\begin{array}{l}0.259^{* *} \\
(2.28)\end{array}$ & $\begin{array}{l}0.265^{* *} \\
(2.31)\end{array}$ & $\begin{array}{l}0.256^{* *} \\
(2.25)\end{array}$ \\
\hline Asian & $\begin{array}{l}0.0249 \\
(0.19)\end{array}$ & $\begin{array}{l}0.0271 \\
(0.21)\end{array}$ & $\begin{array}{l}0.0360 \\
(0.28)\end{array}$ \\
\hline Black & $\begin{array}{l}0.255^{*} \\
(1.80)\end{array}$ & $\begin{array}{l}0.262^{*} \\
(1.83)\end{array}$ & $\begin{array}{l}0.263^{*} \\
(1.85)\end{array}$ \\
\hline income & $\begin{array}{c}0.00519^{* *} \\
(3.38)\end{array}$ & $\begin{array}{c}0.00520^{* *} \\
(3.41)\end{array}$ & $\begin{array}{c}0.00511^{* *} \\
(3.27)\end{array}$ \\
\hline NorthE & $\begin{array}{c}0.0420 \\
(0.61)\end{array}$ & $\begin{array}{c}0.0370 \\
(0.53)\end{array}$ & $\begin{array}{c}0.0656 \\
(1.01)\end{array}$ \\
\hline NorthW & $\begin{array}{c}0.0500 \\
(0.78)\end{array}$ & $\begin{array}{l}0.0521 \\
(0.82)\end{array}$ & $\begin{array}{c}0.0414 \\
(0.63)\end{array}$ \\
\hline Yorks & $\begin{array}{l}0.0857 \\
(1.41)\end{array}$ & $\begin{array}{l}0.0828 \\
(1.35)\end{array}$ & $\begin{array}{l}0.0950 \\
(1.56)\end{array}$ \\
\hline
\end{tabular}


Table 4. Continued

\begin{tabular}{cccc}
\hline & happy & happy & happy \\
\hline \hline EMid & 0.0793 & 0.0713 & $0.118^{*}$ \\
& $(1.22)$ & $(1.06)$ & $(1.94)$ \\
WMid & 0.0775 & 0.0763 & 0.0826 \\
& $(1.26)$ & $(1.24)$ & $(1.34)$ \\
East & 0.0242 & 0.0204 & 0.0445 \\
& $(0.39)$ & $(0.33)$ & $(0.75)$ \\
SouthE & 0.0142 & 0.0101 & 0.0386 \\
& $(0.24)$ & $(0.17)$ & $(0.69)$ \\
SouthW & $0.124^{* *}$ & $0.126^{* *}$ & $0.119^{*}$ \\
& $(2.04)$ & $(2.09)$ & $(1.89)$ \\
lillharm & $-0.426^{* *}$ & $-0.431^{* *}$ & $-0.406^{* *}$ \\
& $(-10.28)$ & $(-10.71)$ & $(-8.57)$ \\
volwork & 0.0353 & 0.0412 & 0.00879 \\
& $(0.83)$ & $(1.02)$ & $(0.17)$ \\
constant & $7.035^{* *}$ & $7.037^{* *}$ & $6.970^{* *}$ \\
& $(25.80)$ & $(26.04)$ & $(24.14)$ \\
\hline $\mathrm{n}$ & 14,913 & 14,913 & 14,913 \\
$\mathrm{R}^{2}$ & 0.0670 & 0.0606 & 0.0110 \\
Wald $\chi^{2}(30)$ & $1,219.27$ & $1,209.58$ & $1,177.51$ \\
Prob $>\chi^{2}$ & 0.000 & 0.000 & 0.000 \\
\hline$t$ statistics in parentheses (based on robust standard errors) & \\
${ }^{* *} p<0.05,{ }^{*} p<0.1$ & & &
\end{tabular}


Table 5. Marginal and Total Values

\begin{tabular}{|c|c|c|c|}
\hline Endogenous variable & Value $(£ 000)$ & Minutes & $\begin{array}{c}\text { Total } \\
\text { Value } \\
(£ 000)\end{array}$ \\
\hline Anysport & $£ 0.11$ & 412.88 & £45.42 \\
\hline Low intensity & $£ 0.14$ & 334.13 & $£ 47.62$ \\
\hline $3 \times 30$ minutes & $£ 1.27$ & 29.32 & $£ 37.30$ \\
\hline
\end{tabular}

